\title{
GTP-mediated $\mathrm{Ca}^{2+}$ release in rough endoplasmic reticulum
}

\author{
Correlation with a GTP-sensitive increase in membrane permeability
}

\author{
Christopher V. NICCHITTA, Suresh K. JOSEPH and John R. WILLIAMSON* \\ Department of Biochemistry and Biophysics, University of Pennsylvania School of Medicine, Philadelphia, PA 19104, U.S.A.
}

\begin{abstract}
Guanine nucleotides have been reported to stimulate reticular $\mathrm{Ca}^{2+}$ release. By using the structure-linked latency of microsomal mannose-6-phosphate phosphatase as an index of microsomal permeability [Arion, Ballas, Lange \& Wallin (1976) J. Biol. Chem. 251, 4901-4907], the effects of GTP on $\mathrm{Ca}^{2+}$ release and membrane permeability were compared in liver microsomes. In a stripped rough-microsome preparation, GTP caused a dose-dependent increase in mannose 6-phosphate permeability. Half-maximal and maximal effects were observed at $3 \mu \mathrm{M}$ - and $10 \mu \mathrm{M}$-GTP respectively. The time course of the change in membrane permeability coincided with the time course of GTP-dependent $\mathrm{Ca}^{2+}$ release. This increase in microsomal permeability displayed positive co-operativity with respect to GTP (Hill coefficient $=1.8$ ). By analogy to the GTP-dependent $\mathrm{Ca}^{2+}$ release process, guanosine $5^{\prime}$-[ $\gamma$-thio]triphosphate and guanosine $5^{\prime}$-[ $\beta \gamma$-imido]triphosphate inhibited the ability of GTP to alter microsomal permeability, but were without effect when added alone. In the presence of $50 \mu \mathrm{M}$-GTP, complete inhibition of the GTP-dependent increase in microsomal permeability was achieved with $10 \mu \mathrm{M}$-guanosine $5^{\prime}$-[ $\gamma$-thio $]$ triphosphate, whereas a $25 \%$ inhibition was observed with $10 \mu \mathrm{M}$-guanosine $5^{\prime}$-[ $\beta \gamma$-imido]triphosphate. In contrast with previous observations in crude microsomal preparations, GTP-dependent $\mathrm{Ca}^{2+}$ release in the stripped roughmicrosome preparation did not require the addition of poly(ethylene glycol), although the latter did stimulate the rate of $\mathrm{Ca}^{2+}$ release. The ability of GTP to alter microsomal permeability was blocked by prior treatment with the thiol reagent $p$-hydroxymercuribenzoate; complete inhibition was observed after a 10 min exposure to $50 \mu \mathrm{M}$. Inhibition was reversed by subsequent treatment with dithiothreitol. The marked similarities between the two GTP-sensitive processes indicate that they may function via the same mechanism.
\end{abstract}

\section{INTRODUCTION}

Guanine nucleotides serve an essential regulatory function in the control of a variety of biochemical processes, ranging from polypeptide initiation and elongation (Pain, 1986; Miller \& Weissbach, 1977) to receptor-dependent transmembrane signal transduction (Rodbell, 1980; Ross \& Gilman, 1980). Several reports have indicated that guanine nucleotides may also regulate $\mathrm{Ca}^{2+}$ transport across the endoplasmic reticulum. After the initial observation by Dawson and co-workers that GTP enhances $\mathrm{IP}_{3}$-mediated $\mathrm{Ca}^{2+}$ release (Dawson, 1985), it has subsequently been shown that GTP can itself stimulate reticular $\mathrm{Ca}^{2+}$ release (Dawson et al., 1986; Ueda et al., 1986; Gill et al., 1986).

In all systems studied to date, including microsomes (microsomal fractions) derived from rat liver (Dawson, 1985; Dawson et al., 1986; Henne \& Söling, 1986), neuroblastoma $\times$ glioma hybrid cells (Ueda et al., 1986; Jean \& Klee, 1986), guinea-pig parotid gland (Henne \& Söling, 1986), as well as permeabilized pancreatic islets (Wolf et al., 1987) and macrophages (Hamachi et al., 1987), GTP-dependent $\mathrm{Ca}^{2+}$ release displays an unusually high nucleotide specificity. In these cell types the nonhydrolysable GTP analogues, GTP[S] and p[NH]ppG, not only are incapable of supporting $\mathrm{Ca}^{2+}$ release but also have been shown to block the effects of GTP (Dawson, 1985; Ueda et al., 1986; Henne \& Söling, 1986; Jean \& Klee, 1986; Wolf et al., 1987). In addition, GTP is effective at low concentrations; maximal $\mathrm{Ca}^{2+}$ release is commonly observed at $10 \mu \mathrm{M}$-GTP (Chueh \& Gill, 1986; Wolf et al., 1987; Hamachi et al., 1987). In isolated microsomes, and in contrast with permeabilized cells, GTP-dependent $\mathrm{Ca}^{2+}$ release is wholly dependent on the presence of poly(ethylene glycol) (PEG) (Dawson, 1985; Ueda et al., 1986; Henne \& Söling, 1986). This agent is not unique, however, since it can be replaced by serum albumin or polyvinylpyrrolidone (Henne \& Söling, 1986).

The effects of GTP on the activity of biochemical processes associated with the endoplasmic reticulum are not limited to $\mathrm{Ca}^{2+}$ release. In addition to its role in the regulation of protein synthesis, GTP has also been shown to enhance core glycosylation (Godelaine et al., $1977,1979 a, b)$. This phenomenon, which occurs in purified rough endoplasmic reticulum stripped of attached ribosomes, has been shown to be strongly correlated with a GTP-dependent increase in the permeability of the endoplasmic reticulum to the sugar nucleotide precursors of the core glycosylation pathway

Abbreviations used: $\mathrm{IP}_{3}$, inositol 1,4,5-trisphosphate; GTP[S], guanosine $5^{\prime}$-[ $\gamma$-thio]triphosphate; $[\mathrm{NH}] \mathrm{ppG}$, guanosine $5^{\prime}$-[ $\beta \gamma$-imido]triphosphate; PEG, poly(ethylene glycol); CHAPS, 3-[3-cholamidopropyl)dimethylammonio]-1-propanesulphonate; PHMB, p-hydroxymercuribenzoate; M6Pase, mannose-6-phosphatase.

* To whom correspondence should be addressed. 
(Godelaine et al., 1983). Thus stripped rough microsomes, incubated in the presence of GTP, UDP- $N$ acetylglucosamine and GDP-mannose, will synthesize dolichyl-pyrophosphate-linked oligosaccharides. In the absence of GTP, little assembly of such precursors is observed (Godelaine et al., 1983). In the present study, the effects of GTP on microsomal $\mathrm{Ca}^{2+}$ release and membrane permeability have been compared to determine whether these responses were mediated by a shared mechanism, or, alternatively, whether these processes were regulated by similar but distinct mechanisms.

\section{MATERIALS AND METHODS}

\section{Preparation of microsomal fractions}

Liver microsomes were prepared from male SpragueDawley rats (180-220 g) as follows. Animals were anaesthetized by intraperitoneal injection of Nembutal, and the livers were excised and minced in ice-cold $0.25 \mathrm{M}$-sucrose/ $5 \mathrm{~mm}$-Tris/Hepes/0.5 m M-EGTA, pH 7.2 (buffer A). A $10 \%$ (w/v) homogenate in buffer A was prepared with a motor-driven $(660 \mathrm{rev} . / \mathrm{min})$ Teflon/ glass homogenizer. The homogenate was centrifuged for $5 \mathrm{~min}$ at $1000 \mathrm{~g}$, the pellet was discarded, and the supernatant was centrifuged for $10 \mathrm{~min}$ at $12000 \mathrm{~g}$. The resulting pellet was discarded and the supernatant was centrifuged for $45 \mathrm{~min}$ at $60000 \mathrm{~g}$. The microsome pellet, termed 'crude microsomes', was either used immediately or resuspended in $1.4 \mathrm{M}$-sucrose $/ 5 \mathrm{~mm}$-Tris/Hepes (pH 7.2) to a final sucrose concentration of $1.38 \mathrm{M}$ for subfractionation into rough and smooth endoplasmic reticulum. Subfractionation of the crude microsome preparation was performed on discontinuous sucrose gradients; $10 \mathrm{ml}$ of the microsome suspension in $1.38 \mathrm{M}$ sucrose/5 mM-Tris/Hepes was overlayered with $10 \mathrm{ml}$ of $1.0 \mathrm{M}$-sucrose/5 mM-Tris/Hepes (pH 7.2) and $5 \mathrm{ml}$ of buffer A. Gradients were centrifuged for $150 \mathrm{~min}$ at $100000 \mathrm{~g}$ in a Beckman SW27 swinging-bucket rotor. The pellet from this centrifugation step, consisting predominantly of rough endoplasmic reticulum, was resuspended in buffer A to a concentration of approx. $10 \mathrm{mg} / \mathrm{ml}$. Attached ribosomes were stripped by addition of $0.5 \mathrm{M}$-Tris/EDTA ( $\mathrm{pH}$ 7.2) to a final EDTA concentration of $3 \mathrm{mM}$. After incubation on ice for $30 \mathrm{~min}$, microsomes were pelleted by centrifugation for $30 \mathrm{~min}$ at $100000 \mathrm{~g}$. The microsome pellet was resuspended in buffer A plus $3 \mathrm{~mm}$-Tris/EDTA and re-pelleted. The microsome preparation was washed once in EDTA-free buffer $A$, and resuspended to a final concentration of $5 \mathrm{mg} / \mathrm{ml}$. Stripped rough microsomes were either used immediately or stored in $0.5 \mathrm{ml}$ batches under liquid $\mathrm{N}_{2}$. The efficacy of the stripping procedure was confirmed by electron microscopy of the stripped and unstripped rough-endoplasmic-reticulum fractions.

\section{Incubation conditions}

The effects of GTP on both microsomal $\mathrm{Ca}^{2+}$ transport and membrane permeability were assayed in a buffer consisting of $0.15 \mathrm{M}$-sucrose, $50 \mathrm{mM}-\mathrm{KCl}, 10 \mathrm{~mm}$-Hepes/ $\mathrm{KOH}$ (pH 7.2), 4 mM- $\mathrm{MgCl}_{2}$, supplemented with $10 \mathrm{~mm}-$ phosphoenolpyruvate, 10 units of pyruvate kinase $/ \mathrm{ml}$, $1 \mathrm{~mm}$-ATP and $2 \mathrm{~mm}$-dithiothreitol, with or without 50 $\mu \mathrm{M}-\mathrm{GTP}$. Microsomes, in buffer A, were added to a final concentration of $1 \mathrm{mg} / \mathrm{ml}$. All incubations were performed at $30^{\circ} \mathrm{C}$. $\mathrm{Ca}^{2+}$ transport was assayed in a
Table 1. Effects of GTP and PEG on the structure-linked latency of M6Pase activity: comparison of crude and rough stripped microsomes

Microsomes ( $1 \mathrm{mg}$ of protein $/ \mathrm{ml}$ ) were incubated in a final volume of $0.1 \mathrm{ml}$ for $15 \mathrm{~min}$ at $30^{\circ} \mathrm{C}$. At this time $1 \mathrm{mM}$ mannose 6-phosphate containing 20000 c.p.m. of mannose 6-[32 P]phosphate was added, and the incubation was continued for an additional $30 \mathrm{~min}$. Incubations were quenched by addition of $0.29 \mathrm{ml}$ of $5 \% \mathrm{HClO}_{4} \cdot\left[{ }^{32} \mathrm{P}\right] \mathrm{P}_{1}$ release was assayed in neutralized extracts as described in the Materials and Methods section. Each value represents the mean \pm S.E.M. for six determinations on two microsomal preparations; n.d., not determined.

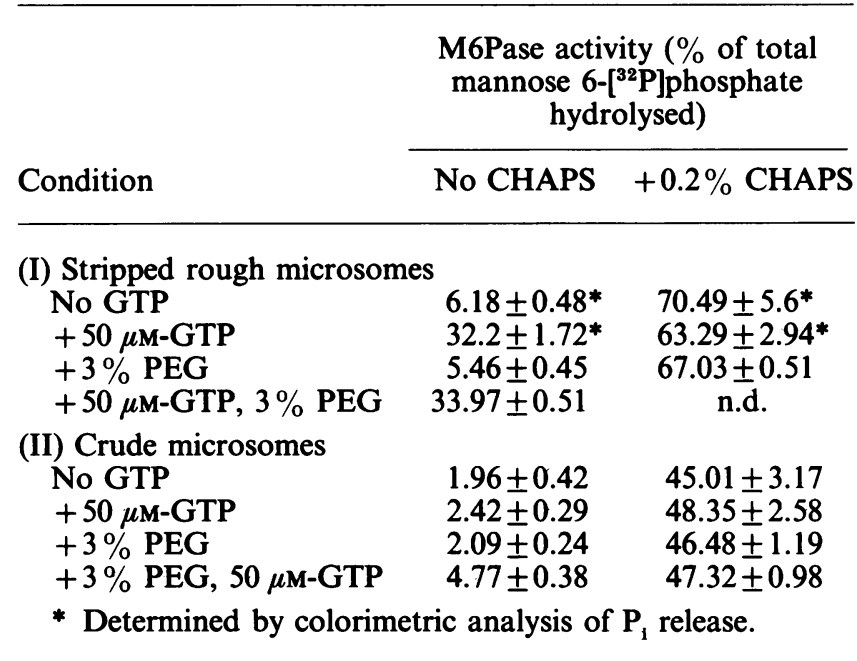

thermostatically controlled chamber with a $\mathrm{Ca}^{2+}$-sensitive micro-electrode. Electrode traces were calibrated as described in Prentki et al. (1983).

\section{Mannose-6-phosphatase assay}

(I) Colorimetric assay. Portions $(50 \mu \mathrm{l})$ of incubation mixtures ( $50 \mu \mathrm{g}$ of microsomal protein) were added to $200 \mu$ l of assay buffer of the following composition (final concns.): $0.25 \mathrm{M}$-sucrose, $20 \mathrm{~mm}$-Pipes (pH 6.5), $1 \mathrm{~mm}$ EDTA, 5 mm-mannose 6-phosphate. Blanks were performed in the absence of mannose 6-phosphate. To determine total mannose-6-phosphatase (M6Pase) activity, the assay buffer was supplemented with CHAPS to a final concentration of $0.2 \%$. Assays were performed for $15 \mathrm{~min}$ at $30^{\circ} \mathrm{C}$ and quenched by addition of $1 \mathrm{ml}$ of ice-cold $10 \%(\mathrm{w} / \mathrm{v})$ trichloroacetic acid/2\% (w/v) ascorbic acid. After centrifugation (1 min at $8000 \mathrm{~g}$ ), $1 \mathrm{ml}$ portions of the supernatant were assayed for $P_{1}$ by the procedure of Baginski et al. (1974).

(II) Radioisotopic determination. Because of extremely high interference with the colorimetric assay, experiments conducted in the presence of PEG were performed with ${ }^{32} \mathrm{P}$-labelled mannose 6-phosphate, prepared essentially as described by Arion et al. (1972). The incubation mixture contained, in a final volume of $0.5 \mathrm{ml}, 20 \mathrm{~mm}$ mannose, $1 \mathrm{~mm}$-ATP, $3 \mathrm{~mm}-\mathrm{MgCl}_{2}, 30 \mathrm{~mm}$-Tris/Hepes (pH 7.2), 20 units of hexokinase and $20 \mu \mathrm{Ci}$ of $\left[\gamma^{-32} \mathrm{P}\right] A T P$. After incubation for $30 \mathrm{~min}$ at $30^{\circ} \mathrm{C}$, the reaction was quenched by addition of $\mathrm{HClO}_{4}$ (final concn. $3.5 \%$, w/v). The sample was neutralized with $\mathrm{KOH}$, and the neutralized extract was applied to a $5 \mathrm{ml}$ column of QAE-Sepharose. After elution of 


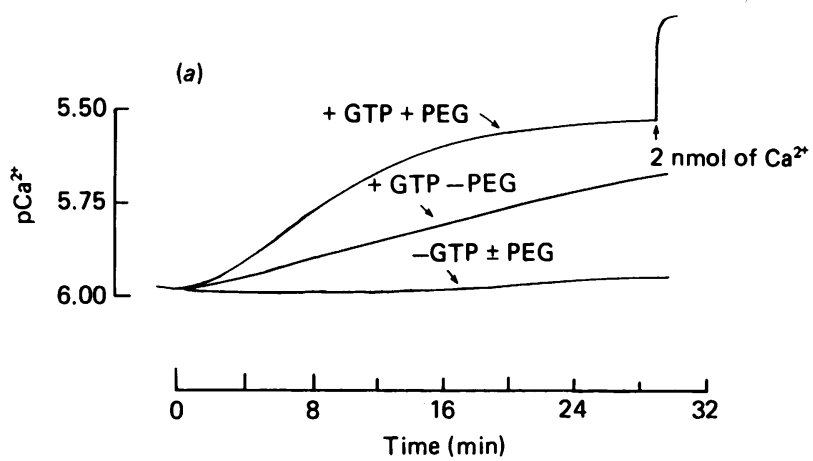

(b)

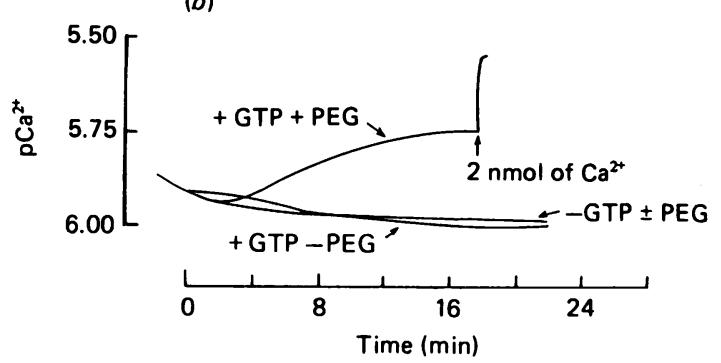

Fig. 1. Comparison of the $\mathrm{Ca}^{2+}$-transport properties of $(b)$ crude and $(a)$ stripped rough microsomes: effects of GTP and PEG

Microsomes ( $1 \mathrm{mg}$ of protein $/ \mathrm{ml}$ ) were incubated in a final volume of $0.15 \mathrm{ml}$ at $30^{\circ} \mathrm{C}$ as described in the Materials and methods section. When present, the GTP concentration was $50 \mu \mathrm{M}$; the PEG concentration was $3 \%(w / v)$. The free $\mathrm{Ca}^{2+}$ in the medium was determined with a $\mathrm{Ca}^{2+}$ sensitive electrode. Electrode traces were calibrated by determining the electrode response in authentic $\mathrm{pCa}^{2+}$ buffers.

free mannose with $3 \times 1.5 \mathrm{ml}$ of $50 \mathrm{~mm}-\mathrm{NH}_{4} \mathrm{HCO}_{3}$, mannose 6-phosphate was eluted with $4 \times 1.5 \mathrm{ml}$ washes of $100 \mathrm{~mm}-\mathrm{NH}_{4} \mathrm{HCO}_{3}$. Column fractions were pooled and dried under vacuum. The final product contained approx. $6 \%\left[{ }^{32} \mathrm{P}\right] \mathrm{P}_{\mathrm{i}}$ and was free of radiolabelled ATP. Hydrolysis of mannose 6-phosphate was assayed as release of $\left[{ }^{32} \mathrm{P}\right] \mathrm{P}_{\mathrm{i}}$. Radiolabelled mannose 6-phosphate was separated from $\left[{ }^{32} \mathrm{P}\right] \mathrm{P}_{\mathrm{i}}$ on $0.5 \mathrm{ml}$ columns of Dowex AG1-X8 (formate form) anion-exchange resin. Mannose $6-\left[{ }^{32} \mathrm{P}\right]$ phosphate was eluted with $3 \times 2 \mathrm{ml}$ of $80 \mathrm{~mm}-$ ammonium formate/0.1 M-formic acid/20\% (v/v) ethanol, and $\left[{ }^{32} \mathrm{P}\right] \mathrm{P}_{1}$ was eluted with $2 \mathrm{ml}$ of $300 \mathrm{~mm}-$ ammonium formate $/ 0.1 \mathrm{M}$-formic acid $/ 20 \%$ ethanol. Radioactivity was determined by Črenkov counting.

\section{Thiol-reagent studies}

For studies with the thiol reagent $p$-hydroxymercuribenzoate (PHMB), stripped rough microsomes were preincubated at a final concentration of $5 \mathrm{mg} / \mathrm{ml}$ with various concentrations of PHMB. All preincubations were performed on ice. After a $10 \mathrm{~min}$ exposure to PHMB, microsomes were diluted 5-fold in assay buffer (see above) and used immediately.

\section{Materials}

All nucleotides were purchased from Boehringer Mannheim. $\left[\gamma^{32}\right.$ P]ATP (sp. radioactivity $>2000 \mathrm{Ci}$ /

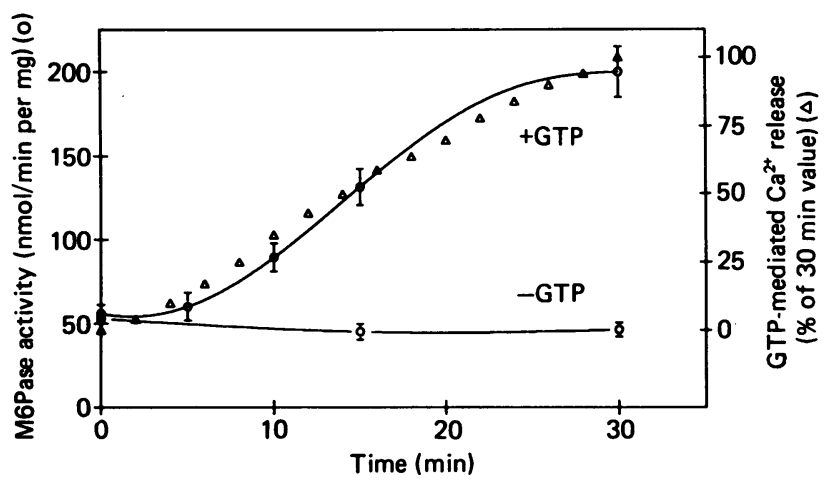

Fig. 2. Comparison of the time course of GTP-dependent $\mathrm{Ca}^{2+}$ release and the GTP-dependent increase in microsomal permeability

M6Pase activity was determined as described in the Materials and methods section. GTP-sensitive $\mathrm{Ca}^{2+}$ release was assayed as described in the legend to Fig. 1. For M6Pase activity each value represents the mean \pm S.D. for three incubations. This experiment was repeated four times with similar results.

mmol) was from Amersham Corp. CHAPS was obtained from Pierce Chemical Co. All other reagents were of the highest quality commercially available.

\section{RESULTS}

\section{Effects of GTP on microsomal permeability : assay of} M6Pase activity

The structure-linked latency of M6Pase is a welldocumented index of microsomal permeability (Arion et al., 1975, 1976; Nordlie \& Sukalski, 1985). The rationale for this assay is based on the observations that the endoplasmic-reticulum membrane is impermeable to mannose 6-phosphate and that M6Pase activity is localized to the luminal, or cisternal, side of the endoplasmic reticulum. M6Pase activity can thus only be observed when this permeability barrier has been disrupted (Nordlie \& Sukalski, 1985). This assay has been used to compare the effects of GTP on endoplasmicreticulum permeability in crude and in stripped rough microsomes from rat liver.

As shown in Table 1 , in the absence of GTP, over $90 \%$ of the M6Pase activity of crude and stripped rough microsomes was latent. PEG alone had no effect on M6Pase latency in either crude or stripped rough microsomes. Addition of GTP $(50 \mu \mathrm{M})$ increased the M6Pase activity of stripped rough microsomes approx. 5-fold, in agreement with the observations of Godelaine et al. (1983). Under the assay conditions described, PEG did not alter the magnitude of the GTP response of the stripped-rough-microsome preparation. GTP alone did not alter M6Pase activity in the crude microsome fraction. In the presence of $3 \%$ PEG, however, GTP produced a 2-fold increase in M6Pase activity.

In a series of separate experiments with stripped rough microsomes, it was confirmed that the GTP-dependent increase in M6Pase activity was the result of an increase in microsomal permeability rather than a release of enzyme activity into the extravesicular space. In these experiments, microsomes were incubated for $45 \mathrm{~min}$ in the presence or absence of GTP, isolated by ultra- 

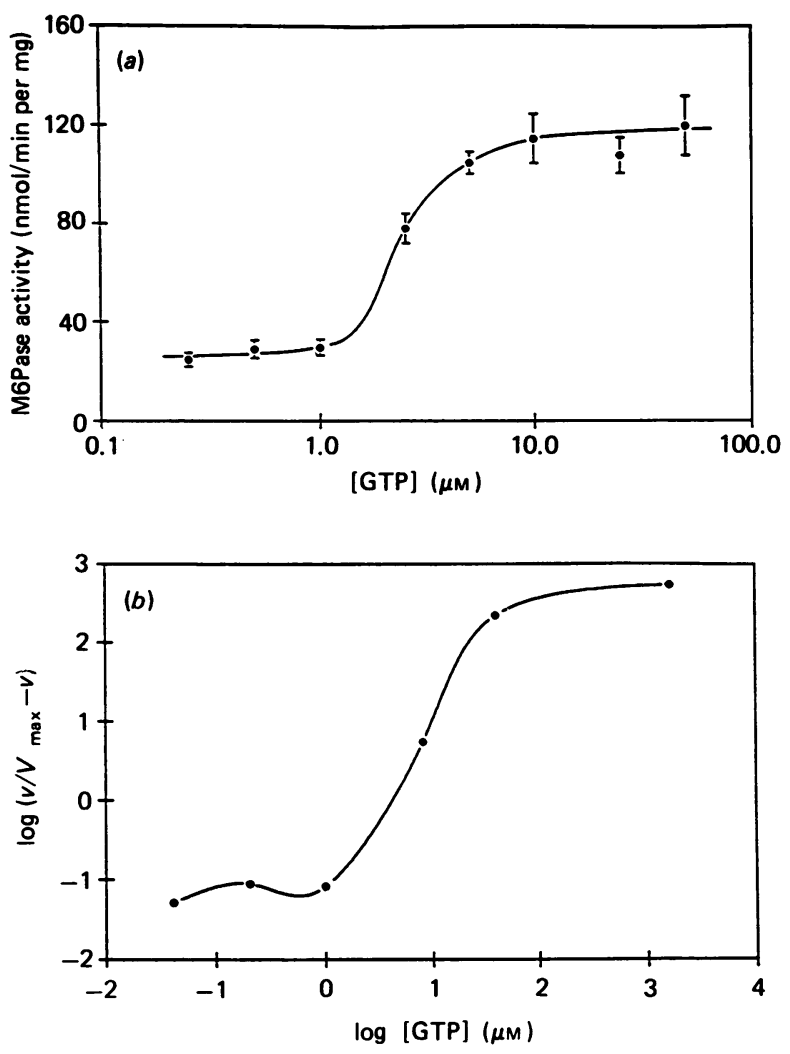

Fig. 3. (a) Dose/response curve of the effects of GTP on the structure-linked latency of MgPase activity; (b) Hill plot of the effects of GTP on the structure-linked latency of M6Pase activity

Incubation and assay conditions were as described in the Materials and methods section. Each data point represents the mean \pm S.D. for three incubations. This experiment was repeated three times with similar results.

centrifugation ( $100000 \mathrm{~g}$ for $30 \mathrm{~min}$ ) and M6Pase activity was assayed in the supernatant and in the detergentsolubilized pellet. GTP was found to have no effect on the distribution of enzyme activity. In the membrane fraction, M6Pase activity was $275 \pm 16.7(n=6) \mathrm{nmol} /$ min per $\mathrm{mg}$ in the absence of GTP and $290 \pm 11.4$ $(n=6) \mathrm{nmol} / \mathrm{min}$ per $\mathrm{mg}$ in the presence of GTP. In the supernatant, M6Pase activity was $19.3 \pm 0.4(n=6)$ and $19.6 \pm 1.2(n=6) \mathrm{nmol} / \mathrm{min}$ per $\mathrm{mg}$ in the presence and absence of GTP respectively.

\section{Effects of GTP and PEG on microsomal $\mathrm{Ca}^{2+}$ transport: comparison of crude and stripped rough microsomes}

$\mathrm{Ca}^{2+}$-electrode traces of the $\mathrm{Ca}^{2+}$-transport behaviour of stripped rough microsomes and crude microsomes are shown in Fig. $1(a)$ and $1(b)$ respectively. In agreement with previous studies (Dawson, 1985; Dawson et al., 1986; Ueda et al., 1986; Henne \& Söling, 1986), crude microsomes, incubated in the presence of $3 \%$ PEG, release sequestered $\mathrm{Ca}^{2+}$ on addition of GTP (Fig. $1 b$ ). $\mathrm{Ca}^{2+}$ release occurred after a short lag and was complete within approx. $10 \mathrm{~min}$. As observed by others (Dawson, 1985; Dawson et al., 1986; Ueda et al., 1986; Henne \& Söling, 1986), GTP-dependent $\mathrm{Ca}^{2+}$ release was absolutely dependent on the presence of PEG. The effects

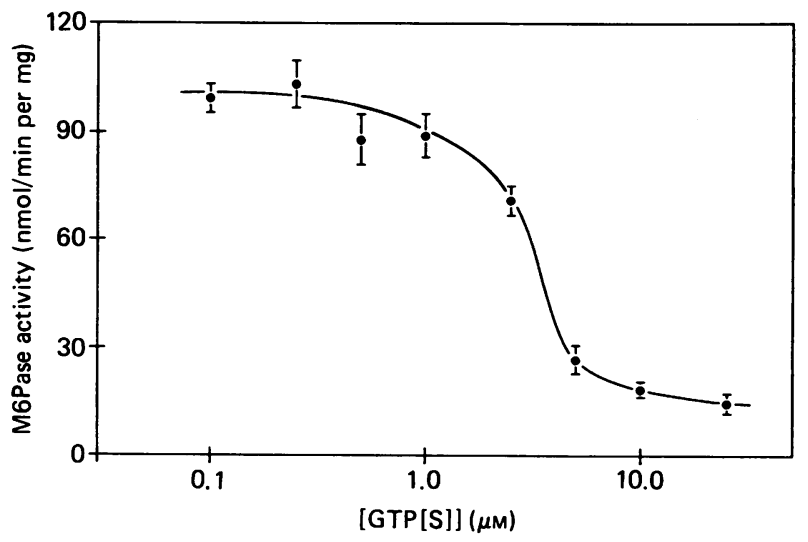

Fig. 4. Effects of GTP[S] on the GTP-dependent decrease in M6Pase latency

Stripped rough microsomes ( $1 \mathrm{mg}$ of protein $/ \mathrm{ml}$ ) were incubated for $30 \mathrm{~min}$ at $30^{\circ} \mathrm{C}$ as described in the Materials and methods section; GTP was present at $50 \mu \mathrm{M}$ final concn. Each value represents the mean \pm S.D. for five incubations.

of GTP on the $\mathrm{Ca}^{2+}$-transport behaviour of stripped rough microsomes are shown in Fig. 1(a). In marked contrast with crude microsomes, stripped rough microsomes exhibit GTP-dependent $\mathrm{Ca}^{2+}$ release in the absence of PEG. PEG did, however, stimulate the process. As observed with crude microsomes, GTP-dependent $\mathrm{Ca}^{2+}$ release in stripped rough microsomes occurred after a short lag period. The release process was somewhat slower than that of crude microsomes, with maximal $\mathrm{Ca}^{2+}$ release in the absence of PEG occurring after 30-40 min exposure to GTP.

Time course of the GTP-dependent decrease in M6Pase latency: comparison with GTP-mediated $\mathrm{Ca}^{2+}$ release

The time course of the GTP-dependent decrease in M6Pase latency and stimulation of $\mathrm{Ca}^{2+}$ release is shown in Fig. 2. In a given preparation of stripped rough microsomes, both phenomena followed a similar time course and exhibited a short lag $(<5 \mathrm{~min})$ after addition of GTP. Half-maximal and maximal responses were observed after 14-18 min and 30-40 min respectively. In the absence of GTP, M6Pase latency was maintained for the time course of the experiment.

\section{GTP-concentration-dependence of M6Pase activity}

The GTP-concentration-dependence for the GTPdependent stimulation of M6Pase activity is shown in Fig. 3(a). The half-maximal and maximal increase in M6Pase activity was observed at $3 \mu \mathrm{M}$ - and $10 \mu \mathrm{M}$-GTP respectively. These values are very similar to those reported for GTP-dependent $\mathrm{Ca}^{2+}$ release (Gill et al., 1986; Chueh \& Gill, 1986; Wolf et al., 1987; Hamachi et al., 1987). A Hill plot of the data presented in Fig. 3(a) is shown in Fig. 3(b). The slope of the plot in the region of $50 \%$ saturation is approx. 1.8 , indicating that the system exhibits positive co-operativity.

\section{Inhibition of the GTP-dependent increase of M6Pase} activity by GTP[S]

A prominent characteristic of the GTP-mediated $\mathrm{Ca}^{2+}$ release process resides in the interaction of this system 
Table 2. Nucleotide specificity of the GTP-dependent decrease in the structure-linked latency of M6Pase

Stripped rough microsomes $(1 \mathrm{mg}$ of protein $/ \mathrm{ml}$ ) were incubated for $30 \mathrm{~min}$ at $30^{\circ} \mathrm{C}$ as described in the Materials and methods section. Each value represents the mean \pm S.D. for four incubations.

\begin{tabular}{lc}
\hline Condition & $\begin{array}{c}\text { M6Pase activity } \\
\text { (nmol/min per mg) }\end{array}$ \\
\hline$+0.2 \%$ CHAPS & $293 \pm 13.0$ \\
No GTP & $29.7 \pm 1.6$ \\
$+50 \mu \mathrm{M}-$ GMP & $39.3 \pm 1.0$ \\
$+50 \mu \mathrm{M}-$ GDP & $145.5 \pm 12.1$ \\
$+50 \mu \mathrm{M}-\mathrm{GTP}$ & $170.9 \pm 6.6$ \\
$+50 \mu \mathrm{M}-\mathrm{p}[\mathrm{NH}] \mathrm{ppG}$ & $31.0 \pm 1.2$ \\
$+50 \mu \mathrm{M}-\mathrm{GTP}[\mathrm{S}]$ & $13.4 \pm 0.8$ \\
$+50 \mu \mathrm{M}-\mathrm{ITP}$ & $30.9 \pm 2.3$ \\
$+50 \mu \mathrm{M}-\mathrm{GTP}, 10 \mu \mathrm{M}-\mathrm{p}[\mathrm{NH}] \mathrm{ppG}$ & $130.9 \pm 12.2$ \\
$+50 \mu \mathrm{M}-\mathrm{GTP}, 10 \mu \mathrm{M}-\mathrm{GTP}[\mathrm{S}]$ & $40.5 \pm 0.6$ \\
\hline
\end{tabular}

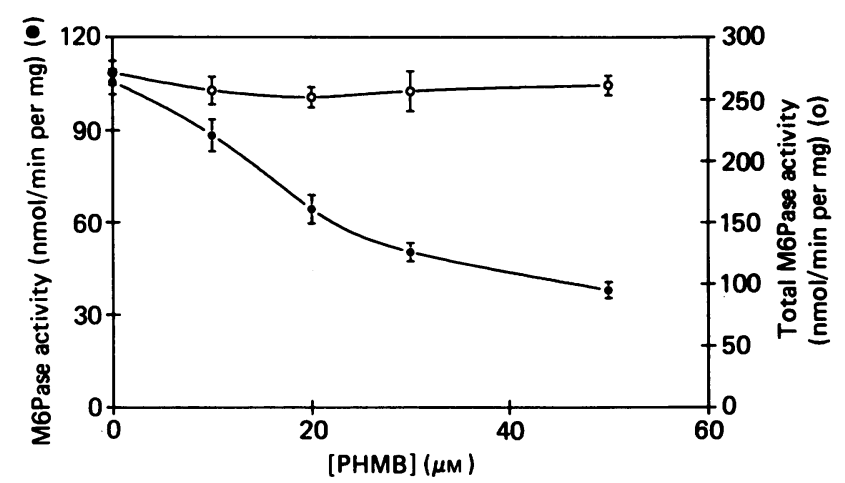

Fig. 5. Effects of PHMB treatment on the GTP-sensitive decrease in M6Pase latency

Stripped rough microsomes $(5 \mathrm{mg}$ of protein $/ \mathrm{ml}$ ) were treated for $10 \mathrm{~min}$ at $0^{\circ} \mathrm{C}$ with various concentrations of the thiol reagent PHMB. Microsomes were then diluted 5fold $(1 \mathrm{mg}$ of protein $/ \mathrm{ml}$ ) and assayed for GTP-dependent changes in M6Pase latency as described in the Materials and methods section. Basal M6Pase activity, determined in the absence of GTP and PHMB, was $36.2 \pm 4.1 \mathrm{nmol} /$ min per $\mathrm{mg}(n=4)$.

with non-hydrolysable GTP analogues. Several investigators have reported that non-hydrolysable GTP analogues, although ineffective by themselves in promoting $\mathrm{Ca}^{2+}$ release, block the action of GTP, with GTP[S] being a far more potent inhibitor of GTPmediated $\mathrm{Ca}^{2+}$ release than p[NH]ppG (Dawson, 1985; Chueh \& Gill, 1986). As shown in Fig. 4, GTP[S] inhibited the GTP-dependent stimulation of M6Pase activity. In the presence of $50 \mu \mathrm{M}-\mathrm{GTP}$, half-maximal inhibition was observed at $3 \mu \mathrm{M}$ and maximal inhibition was obtained at $10 \mu \mathrm{M}-\mathrm{GTP}[\mathrm{S}]$.

\section{Nucleotide specificity}

The nucleotide specificity of the GTP-dependent increase in M6Pase activity is described in Table 2. Of the assayed nucleotides, only GDP and GTP were capable of stimulating M6Pase activity. The effects of GDP may reflect the nucleoside-diphosphate-kinase-dependent conversion of GDP into GTP. Substantial activities of this enzyme are present in the microsome preparations (results not shown). Both GTP[S] and p[NH]ppG inhibit the effects of GTP on M6Pase activity. As is clear from Table 2, GTP[S] is a far more potent inhibitor of this response than is $\mathrm{p}[\mathrm{NH}] \mathrm{ppG}$.

\section{Evidence for an essential thiol group in the modulation of endoplasmic-reticulum permeability by GTP}

In order to gain further insight into the mechanism by which GTP alters endoplasmic-reticulum permeability, the thiol-group requirement for this process was investigated. For these experiments, concentrated microsomes were treated with various concentrations of the thiol reagent PHMB, diluted into assay medium and assayed for the GTP-sensitive decrease in M6Pase latency. As shown in Fig. 5, PHMB pretreatment blocked this response, with half-maximal and maximal effects being observed at $15 \mu \mathrm{M}$ - and $50 \mu \mathrm{M}-\mathrm{PHMB}$ respectively. The inhibitory action of PHMB was not due to effects on M6Pase activity, since total M6Pase activity was unaffected by this reagent. The PHMB-dependent inhibition could be reversed by addition of $2 \mathrm{~mm}$-dithiothreitol (results not shown). Attempts to prevent the inhibitory effects of PHMB by prior addition of GTP $(30 \mu \mathrm{M})$ or GTP[S] (5 $\mu \mathrm{M})$ were unsuccessful (results not shown).

\section{DISCUSSION}

Several studies have indicated that the effects of GTP and $\mathrm{IP}_{3}$ on reticular $\mathrm{Ca}^{2+}$ release may be mediated by distinct, albeit undefined, mechanisms (Henne \& Söling, 1986; Chueh \& Gill, 1986; Jean \& Klee, 1986). This conclusion arises from comparison of a number of the characteristics of the release process, including temperature-sensitivity, the requirement for PEG, the interaction with non-hydrolysable GTP analogues, and the regulation by extravesicular free $\mathrm{Ca}^{2+}$.

Differences in temperature-sensitivity are commonly used to differentiate between channel- and carriermediated transport processes. On the basis of this criterion, it has been proposed that the $\mathrm{IP}_{3}$-mediated $\mathrm{Ca}^{2+}$-release process has the properties of a ligand-gated $\mathrm{Ca}^{2+}$ channel (Brass \& Joseph, 1985; Smith et al., 1985; Joseph \& Williamson, 1986). Henne \& Söling (1986) have observed that GTP-dependent $\mathrm{Ca}^{2+}$ release in guinea-pig parotid microsomes differs from the $\mathrm{IP}_{3}$-gated mechanism in that the GTP-dependent response displays a high temperature-sensitivity. These observations have been confirmed by Chueh \& Gill (1986) in a saponinpermeabilized N1E-115 cell preparation. Such a high temperature-dependence would be expected if the GTPsensitive $\mathrm{Ca}^{2+}$ release process involved either an enzymic reaction(s) and/or a diffusion-limited interaction of protein components within the reticular membrane. Differences in temperature-sensitivity alone, however, are insufficient evidence for concluding that the two release processes are wholly distinct. It is conceivable that both release processes may act on a shared population of $\mathrm{Ca}^{2+}$-release sites, with the differences in temperature-sensitivity reflecting distinct regulatory mechanisms. This possibility appears unlikely, since several investigators have reported that the release of $\mathrm{Ca}^{2+}$ in response to $\mathrm{IP}_{3}$ or GTP is independent of the presence of the other reagent (Jean \& Klee, 1986; Ueda 
et al., 1986; Henne \& Söling, 1986). If both release processes mediate the release of $\mathrm{Ca}^{2+}$ from the same site, it would be expected that the release occurring in response to addition of both effectors would be less than additive.

The two $\mathrm{Ca}^{2+}$-release processes can also be distinguished by their sensitivity to inhibition by nonhydrolysable GTP analogues and requirement for PEG. Chueh \& Gill (1986) have reported that, in permeabilized N1E-115 cells, GTP[S] completely blocks the effects of GTP on reticular $\mathrm{Ca}^{2+}$ release, whereas $\mathrm{IP}_{3}$-sensitive $\mathrm{Ca}^{2+}$ release is insensitive to this compound. Similarly, Dawson et al. (1987) have observed that if GTP[S] is added after the addition of GTP, GTP-dependent $\mathrm{Ca}^{2+}$ release by hepatic microsomes is inhibited. Under these conditions the $\mathrm{IP}_{3}$ response is unaltered (Dawson et al., 1987). With respect to PEG, GTP-mediated $\mathrm{Ca}^{2+}$ release displays an absolute requirement for added PEG, polyvinylpyrrolidone or serum albumin (Dawson et al., 1986; Ueda et al., 1986; Henne \& Söling, 1986; Jean \& Klee, 1986). In microsomal fractions isolated from NG 108-15 cells (Jean \& Klee, 1986) and in permeabilized N1E-115 cells (Chueh \& Gill, 1986), $\mathrm{IP}_{3}$-sensitive $\mathrm{Ca}^{2+}$ release does not require added PEG.

Lastly, investigations into the effects of varying the extravesicular free $\mathrm{Ca}^{2+}$ on both GTP- and $\mathrm{IP}_{3}$-sensitive $\mathrm{Ca}^{2+}$ release have indicated that $\mathrm{IP}_{3}$-sensitive $\mathrm{Ca}^{2+}$ release can be inhibited by free $\mathrm{Ca}^{2+}$ in the range $1-10 \mu \mathrm{M}$, whereas GTP-sensitive $\mathrm{Ca}^{2+}$ release is relatively insensitive to variation in the extravesicular free $\mathrm{Ca}^{2+}$ (Jean \& Klee, 1986; Chueh \& Gill, 1986). The two $\mathrm{Ca}^{2+}$-release responses can thus be differentiated by several independent criteria. It therefore appears likely that GTP and $\mathrm{IP}_{3}$ are acting on unique $\mathrm{Ca}^{2+}$-release processes that may be localized to distinct vesicle populations (Jean \& Klee, 1986; Williamson et al., 1986).

In view of previous reports that the permeability of stripped rough microsomes was increased on addition of GTP (Godelaine et al., 1983; Paiement et al., 1987), it was decided to investigate this phenomenon further in relation to GTP-sensitive microsomal $\mathrm{Ca}^{2+}$ release. The studies described in the present paper indicate that the two phenomena are remarkably similar. Both processes (a) display a similar sensitivity to GTP concentration, (b) occur over the same time course, $(c)$ are inhibited by nonhydrolysable GTP analogues under conditions where such nucleotide analogues are themselves ineffective in modulating either increased permeability or $\mathrm{Ca}^{2+}$ release, and $(d)$ have precisely the same nucleotide specificity. On the basis of the described similarities, it therefore appears that the two responses are mediated by very similar, if not identical, regulatory processes.

The question necessarily arises whether the microsome fraction contains two apparently identical, yet distinct, mechanisms for modulating membrane permeability, or whether the GTP-sensitive $\mathrm{Ca}^{2+}$-release process is an attendant response to a GTP-dependent permeability change occurring in the rough endoplasmic reticulum, a process which, physiologically, may be unrelated to $\mathrm{Ca}^{2+}$ transport. Concerning the first possibility, should GTP be regulating two similar but distinct permeability events, it follows that the two systems must be segregated among differing vesicle populations, since it can be assumed that conditions which yield an increase in permeability to mannose 6-phosphate would also result in an increased $\mathrm{Ca}^{2+}$ permeability. Alternatively, the GTP-dependent $\mathrm{Ca}^{2+}$-release responses may reflect the activity of meta- bolic processes other than $\mathrm{Ca}^{2+}$ transport that are associated with the rough endoplasmic reticulum. Potential candidates include core glycosylation (Godelaine et al., 1983), peptide transfer (Blobel, 1980) or processes associated with vesicle sorting and salvage (Warren, 1987).

To date, all studies of GTP-dependent $\mathrm{Ca}^{2+}$ release in isolated microsomal fractions have indicated an obligatory requirement for PEG (Dawson et al., 1986; Ueda et al., 1986; Henne \& Söling, 1986; Jean \& Klee, 1986). Stripped rough microsomes, in contrast, exhibit GTPdependent $\mathrm{Ca}^{2+}$ release in the absence of PEG, although PEG will stimulate this process. This behaviour is very similar to that observed in saponin-permeabilized washed N1E-115 cells (Ueda et al., 1986), where PEG, although not obligatory for observing GTP-dependent $\mathrm{Ca}^{2+}$ release, had a stimulatory effect. These similarities lend credence to the possibility that GTP-dependent $\mathrm{Ca}^{2+}$ release may be mechanistically similar in the permeabilized cell and the stripped rough-microsome preparation. It is important to note that PEGindependent GTP-sensitive microsomal $\mathrm{Ca}^{2+}$ release occurs only after the rough-microsome preparation has been washed in buffer supplemented with EDTA. This treatment is known to remove ribosomes, as well as other peripheral proteins. The requirement for such treatment may be due to the existence of an endogenous inhibitor, or regulator, of the permeability change.

In addition to enhancing core glycosylation, addition of GTP to stripped rough microsomes has also been shown to stimulate membrane fusion (Paiement et al., 1980; Paiement \& Bergeron, 1983). On the basis of the relationship of enhanced core glycosylation with fused microsomes, it has been proposed that the GTPdependent increase in membrane permeability to sugar nucleotides is localized to the reticular fusion products (Paiement \& Bergeron, 1983). It remains to be determined whether the GTP-sensitive increase in membrane permeability precedes the process of fusion, occurs coincidentally, or is simply a characteristic of the fusion product. Previous studies indicated that extensive fusion appeared to require incubation periods up to $120 \mathrm{~min}$ (Paiement \& Bergeron, 1983), and it has been argued that such changes in permeability are temporally distinct from the process of fusion (Godelaine et al., 1983). However, Dawson et al. (1987) have observed that, in the presence of PEG, GTP induced a rapid formation (1 min) of large multilamellar vesicles. It is possible that changes in membrane permeability, core glycosylation and membrane fusion represent a related series of metabolic events that, although dependent on the presence of GTP, occur over distinct time frames.

In summary, the results indicate that in a stripped rough-microsome preparation GTP regulates the permeability of the microsomal membrane. The effects of GTP on microsomal permeability share a marked resemblance to the process of GTP-mediated $\mathrm{Ca}^{2+}$ release, indicating that the $\mathrm{Ca}^{2+}$-release response may reflect the effects of GTP on processes other than $\mathrm{Ca}^{2+}$ transport. Further work is necessary to define the mechanism by which this change in permeability is achieved.

This work was supported by N.I.H. grant DK-15120 (J. R. W.), an Institutional Training Grant HL-07502 (C. V.N.) and N.I.H. grant DK-34804 (S. K.J.). S. K.J. is the recipient of a Career Development Award from the Juvenile Diabetes Foundation International. 


\section{REFERENCES}

Arion W. J., Wallin, B. K., Carlson, P. W. \& Lange, A. J. (1972) J. Biol. Chem. 247, 2558-2565

Arion, W. J., Wallin, B. K., Lange, A. J. \& Ballas, L. M. (1975) Mol. Cell. Biochem. 6, 75-83

Arion, W. J., Ballas, L. M., Lange, A. J. \& Wallin, B. K. (1976) J. Biol. Chem. 251, 4901-4907

Baginski, E. S., Foa, P. P. \& Zak, B. (1974) in Methods of Enzymatic Analysis (Bergmeyer, H. U., ed.), vol. 2, pp. 876-880, Academic Press, New York

Blobel, G. (1980) Proc. Natl. Acad. Sci. U.S.A. 77, 1496-1500

Brass, L. F. \& Joseph, S. K. (1985) J. Biol. Chem. 260, 15.172-15179

Chueh, S.-H. \& Gill, D. L. (1986) J. Biol. Chem. 261, 13883-13886

Dawson, A. P. (1985) FEBS Lett. 185, 147-150

Dawson, A. P., Comerford, J. G. \& Fulton, D. V. (1986) Biochem. J. 234, 311-315

Dawson, A. P., Hills, G. \& Comerford, J. G. (1987) Biochem. J. 244, 87-92

Gill, D. L., Ueda, T., Chueh, S.-H. \& Noel, M. W. (1986) Nature (London) 320, 461-464

Godelaine, D., Beaufay, H. \& Wibo, M. (1977) Proc. Natl. Acad. Sci. U.S.A. 74, 11095-11099

Godelaine, D., Beaufay, H., Wibo, M. \& Amar-Costesec, A. (1979a) Eur. J. Biochem. 96, 17-26

Godelaine, D., Beaufay, H., Wibo, M. \& Amar-Costesec, A. (1979b) Eur. J. Biochem. 96, 27-34

Godelaine, D., Beaufay, H., Wibo, M. \& Ravoet, A.-M. (1983) J. Cell Biol. 97, 340-350

Hamachi, T., Hirata, M., Kimura, Y., Ikebe, T., Ishimatsu, T., Yamaguchi, K. \& Koga, T. (1987) Biochem. J. 242, 253-260

Received 8 June 1987/28 July 1987; accepted 20 August 1987
Henne, V. \& Söling, H.-D. (1986) FEBS Lett. 202, 267-273

Jean, T. \& Klee, C. B. (1986) J. Biol. Chem. 261, 16414-16420

Joseph, S. K. \& Williamson, J. R. (1986) J. Biol. Chem. 261, 14658-14664

Miller, D. L. \& Weissbach, H. (1977) in Molecular Mechanisms of Protein Biosynthesis (Weissbach, H. \& Pestka, S., eds.), pp. 323-373, Academic Press, New York

Nordlie, R. C. \& Sukalski, K. (1985) in The Enzymes of Biological Membranes (Martonosi, A. N., ed.), vol. 2, pp. 349-398, Plenum, New York

Paiement, J. \& Bergeron, J. J. M. (1983) J. Cell Biol. 96, 1791-1796

Paiement, J., Beaufay, H. \& Godelaine, D. (1980) J. Cell Biol. 86, 29-37

Paiement, J., Rindress, D., Smith, C. E., Poliquin, L. \& Bergeron, J. J. M. (1987) Biochim. Biophys. Acta 898, 6-22

Pain, V. M. (1986) Biochem. J. 235, 625-637

Prentki, M., Janjic, D. \& Wollheim, C. B. (1983) J. Biol. Chem. 258, 7597-7602

Rodbell, M. (1980) Nature (London) 284, 17-22

Ross, E. M. \& Gilman, A. G. (1980) Annu. Rev. Biochem. 49, 533-564

Smith, J. B., Smith, L. \& Higgins, B. L. (1985) J. Biol. Chem. 260, 14413-14416

Ueda, T., Chueh, S.-H., Noel, M. W. \& Gill, D. L. (1986) J. Biol. Chem. 261, 3184-3192

Warren, G. (1987) Nature (London) 327, 17-18

Williamson, J. R., Joseph, S. K., Coll, K. E., Thomas, A. P., Verhoeven, A. \& Prentki, M. (1986) in New Insights into Cell and Membrane Transport (Poste, G. \& Crooke, S. T., eds.), pp. 217-247, Plenum, New York

Wolf, B. A., Florholmen, J., Colca, J. R. \& McDaniel, M. L. (1987) Biochem. J. 242, 137-141 